
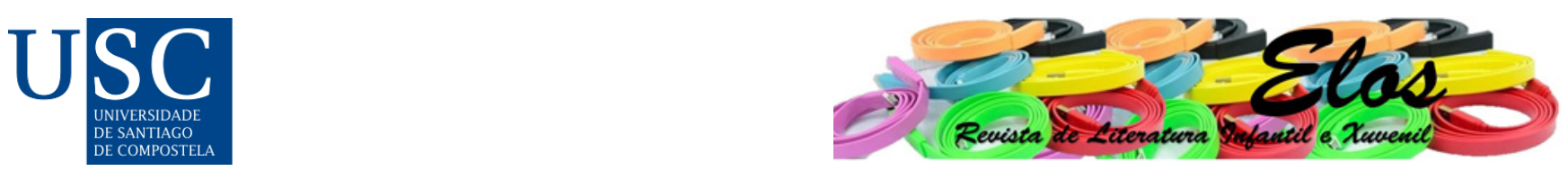

Elos: Revista de Literatura Infantil e Xuvenil, (8), 2021. ISSN-e: 2386-7620

https://doi.org/10.15304/elos.8.7985

Artigos

\title{
Tendências editoriais e impactos de políticas educativas na publicação de Literatura para a Infância em Portugal
}

Tendencias editoriales e impactos de políticas educativas en la publicación de Literatura Infantil en Portugal

Editorial trends and impacts of educational policies on the publication of Children's Literature in Portugal

\author{
Andressa Jove Godoy iD \\ Universidade de Aveiro, Portugal \\ andressa.godoy@ua.pt
}

Recibido: 29/09/2021; Aceptado: 08/11/2021

\section{Resumo}

Este trabalho é fruto de uma pesquisa que analisou obras de Literatura para a Infância de autoria portuguesa dos gêneros poesia e conto de autor. Essa pesquisa teve como objetivos caracterizar o seu percurso editorial e, a partir da observação dos seus peritextos, identificar o impacto editorial recente, decorrente da sua inserção na lista de livros de leitura obrigatória no Programa e nas Metas Curriculares de Português do Ensino Básico. No recorte retratado neste trabalho, são apresentadas as tendências editoriais mercadológicas e estéticas identificadas nas obras que compuseram o corpus e que podem ser generalizadas para um contexto de edição para a infância mais amplo. Dessas tendências, evidencia-se a constatação da importância da legitimação dada pela escola para que obras com menos apelo comercial não sejam esquecidas; algumas repercussões de um mercado editorial bipolarizado e sob o controle de grandes grupos; e as contaminações e ecos estéticos próprios do livro-álbum que se fazem presentes em livros de outros formatos.

Palavras chave: literatura para a infância; edição para a infância; políticas educativas; peritextos.

\section{Resumen}

Este trabajo es el resultado de una investigación que analizó obras de Literatura Infantil de autoría portuguesa en los géneros de poesía y cuento. Esta investigación tuvo como objetivo caracterizar su trayectoria editorial y, a partir de la observación de sus peritextos, identificar el impacto editorial reciente, resultante de su inclusión en la lista de libros de lectura obligatoria del Programa y de las Metas Curriculares de Portugués para la Educación Básica. En el recorte retratado en esta obra se presentan las tendencias editoriales de marketing y estéticas identificadas en las obras que componen el corpus y que pueden generalizarse a un contexto más amplio de la edición para niños. Estas tendencias muestran la importancia de la legitimidad otorgada por la escuela para que no se olviden obras con menor atractivo comercial; algunas repercusiones de un mercado editorial bipolarizado bajo el control de grandes grupos; y las contaminaciones y ecos estéticos característicos del libro-álbum que están presentes en libros de otros formatos. 
Palabras clave: literatura infantil; edición para niños; políticas educativas; peritextos.

\begin{abstract}
This work is the result of a research that analyzed Portuguese poetry and short story books of Children's Literature. This research aimed to characterize its editorial path and, from the observation of its peritexts, identify the recent editorial impact, resulting from its inclusion in the list of mandatory reading books in the Program and in the Curriculum Goals of Portuguese for Basic Education. The results portrayed in this work demonstrate the marketing and aesthetic editorial trends identified in the books presents in the corpus that can be generalized to a wider context of editing for children. These trends show the importance of the legitimacy given by the school so that works with less commercial appeal are not forgotten; some repercussions of a bipolarized publishing market under the control of large groups; and the contaminations and aesthetic echoes characteristic of the picturebook that are present in books of other formats.
\end{abstract}

Keywords: children's literature; publishing for children; educational policies; peritexts.

\title{
INTRODUÇÃO
}

A produção literária voltada para o público infantil está atrelada aos contextos escolares e às instituições de ensino desde o seu princípio, quando livros foram criados e adaptados para serem utilizados como material de apoio no processo de alfabetização das poucas crianças que aprendiam a ler e a escrever à época (Gomes, 1998). A consolidação e o fortalecimento dessa relação concederam à Escola os papeis de legitimador do cânone da Literatura para a Infância (Ramos, 2012) e de mercado seguro e rentável para as casas editoriais (Dauster, 2004). Dessa forma, ao desenvolver, por exemplo, uma lista de livros de leitura obrigatória, as instituições de ensino contribuem para que os títulos que ali figuram sejam considerados obras de qualidade e tenham um público consumidor/leitor estável.

Para além das mencionadas consequências aos níveis literário e mercadológico, o reconhecimento de obras de Literatura para a Infância concedido pelas escolas também pode ser considerado responsável por uma série de outros fenômenos ao nível editorial. Um exemplo é a possibilidade de que sejam publicadas, em decorrência do maior interesse comercial gerado por conta da adoção em contexto escolar, novas edições desses livros, que apresentam entre si diferentes características estéticas, materiais, literárias e de conteúdo, em atenção às tendências artísticas e literárias e às necessidades comerciais, de leitura e de produção de cada época.

De entre as mudanças que uma obra pode apresentar entre suas edições, as mais facilmente reconhecíveis são as assumidas por elementos de caráter estético e material, chamadas por Genette (1997) de peritextos. Segundo o autor, os elementos peritextuais são os paratextos que estão situados "around the text and either within the same volume" (id. Ibid., p. 4). Assim, e ainda de acordo com o autor, elementos como capa, contracapa, lombada e guardas, para além de compor a materialidade do livro, assumindo papeis estruturais, comerciais e editoriais, também compõem e ampliam os significados das obras de que fazem parte.

As contribuições dos peritextos para a construção de significados são ainda mais expressivas e exploradas em livros de Literatura para a Infância, tendo em vista que "features that in adult literature are usually taken by critics to be peripheral to the text, in children's literature are 
deliberately used to enhance the reader's consciousness of the material existence of the text as an object" (Higonnet, 1990, p. 47). Dessa forma, diferenças peritextuais entre edições de um livro de Literatura para a Infância podem corroborar distintas formas de antecipação e extensão de leitura dessa obra.

Com base nesses pressupostos, desenvolveu-se uma pesquisa sob a metodologia de análise de conteúdo (Weber, 1990) a partir do corpus formado pelos livros dos gêneros conto de autor e poesia, de autoria portuguesa, que figuram na Lista de Obras e Textos de leitura obrigatória para os anos escolares do 1. Ciclo, publicada no documento oficial de política educativa Metas Curriculares de Português do Ensino Básico, sancionado em 2012 (Ministério de Educação e Ciência, 2015). A pesquisa teve como objetivo principal realizar a caracterização do percurso editorial das obras que compuseram o corpus e, a partir da análise dos peritextos capa, contracapa, lombada e guardas de cada uma das suas edições significativas, identificar o impacto editorial recente, decorrente da sua inserção na lista de livros de leitura obrigatória ou sugerida no Programa e nas Metas Curriculares de Português do Ensino Básico. É importante ressaltar que foram consideradas significativas aquelas edições que, catalogadas no Depósito Legal da Biblioteca Nacional de Portugal, fossem ilustradas por diferentes ilustradores, publicadas por diferentes editoras ou materializadas em diferentes formatos, resultando em livros distintos também.

Neste artigo, são apresentados os principais resultados e discussões gerados a partir da realização da referida pesquisa, tendo em atenção, principalmente, as tendências observadas no corpus que possam ser identificadas num contexto mais global de edição de Literatura para a Infância. Dessa forma, em Obras relembradas, são observados os percursos editoriais dos livros que foram reeditados somente após a sua adoção como leitura obrigatória pelas Metas Curriculares. Os percursos editoriais também são ponto de partida para que, em Duas faces da moeda, sejam explorados os efeitos da bipolarização do mercado editorial português. Já em Ecos do livro-álbum, são abordados exemplos de edições recentes de livros de poesia e conto de autor que foram contaminados pelas características estéticas e materiais do formato livro-álbum.

\section{OBRAS RELEMBRADAS}

A despeito do seu valor cultural e de sua importância estética, lúdica e pedagógica, a Literatura para a Infância ainda ocupa um lugar marginal no sistema literário. Isso acontece graças aos preconceitos motivados pela subvalorização da sua origem na Literatura de tradição oral e das competências leitoras do seu público preferencial, as crianças; e da sua similaridade com práticas literárias pouco ou nada prestigiadas pela crítica (Ramos, 2012).

Apesar dessas diferenças de reconhecimento (que, diga-se de passagem, vêm sendo contestadas por meio de esforços de estudiosos e apreciadores), "a indústria editorial não se configura como se houvesse uma cisão entre editoração adulta e infantil" (Saraiva, 2012, p. 10), tendo em vista que, tanto uma quanto a outra são desenvolvidas tendo como um de seus objetivos o fortalecimento do mercado. Com isso, é possível constatar que, por vezes, a Literatura para a Infância enfrenta adversidades e desafios comerciais análogos aqueles postos à Literatura tout court.

Um dos desafios por elas compartilhado é o lugar aparentemente menos prestigioso ocupado pelas obras de poesia nas editoras e livrarias, muito provavelmente devido ao baixo interesse comercial despertado por esses livros, que, por isso, são menos publicados e reeditados (Sapiro, 2018). 
A resistência mercadológica colocada aos livros de poesia ficou visível na análise do percurso editorial das obras desse gênero que compõem o corpus. Isso, porque, de entre os onze títulos de poesia de autoria portuguesa que constam da Lista de Obras e Textos de leitura obrigatória para os alunos do 1.․ Ciclo em Portugal, quatro foram reeditados apenas após a promulgação das Metas Curriculares em 2012 (sendo eles: As cançõezinhas da Tila e As fadas verdes, de Matilde Rosa Araújo; $O$ rouxinol e sua namorada e Bichos, bichinhos e bicharocos, de Sidónio Muralha) e um não foi reeditado mesmo após a implementação desta política educativa (Mistérios, de Matilde Rosa Araújo), conforme demonstrado no Quadro 1 (Obras de poesia e suas respectivas edições).

Quadro 1. Obras de poesia e suas respectivas edições.

\begin{tabular}{|c|c|}
\hline Identificação & Ediçōes \\
\hline \multirow{6}{*}{$\begin{array}{l}\text { Aquela nuvem e } \\
\text { Outras } \\
\text { Eugénio de Andrade }\end{array}$} & $\begin{array}{l}\text { il. por Júlio Resende. Porto: ASA, } 1986 \text { - Colecção Asa } \\
\text { Juvenil }\end{array}$ \\
\hline & il. Jorge Colombo. Lisboa: Círculo de Leitores, 1989 \\
\hline & $\begin{array}{l}\text { il. Alfredo Martins. Porto: Campo das Letras, } 1999 \text { - } \\
\text { Palmo e Meio }\end{array}$ \\
\hline & $\begin{array}{l}\text { il. Aurélie de Sousa. 1. }{ }^{\mathrm{a}} \text { ed. Porto: Porto Editora, } 2013 \text { - } \\
\text { Coleção Educąão Literária }\end{array}$ \\
\hline & 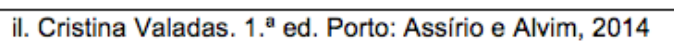 \\
\hline & $\begin{array}{l}\text { il. Aurélie de Sousa. 2. a ed. Porto: Porto Editora, } 2016 \text { - } \\
\text { Coleção Educação Literária }\end{array}$ \\
\hline \multirow{4}{*}{$\begin{array}{l}\text { O livro da Tila } \\
\text { Matilde Rosa Araújo }\end{array}$} & $\begin{array}{l}\text { Lisboa: Editorial Os Nossos Filhos, } 1957 \text { - Colecção } \\
\text { Rouxinol }\end{array}$ \\
\hline & $\begin{array}{l}\text { [...] cantigas pequeninas. } 3^{\text {a }} \text { ed. Coimbra: Atlântida } \\
\text { Editora, } 1973 \text { - Colecção Bandeiras de Todo o mundo }\end{array}$ \\
\hline & $\begin{array}{l}\text { [...] cantigas pequeninas. } 10 .^{\mathrm{a}} \text { ed. Lisboa: Livros } \\
\text { Horizonte, } 1986 \text { - Colecção Obras de Matilde Rosa } \\
\text { Araújo }\end{array}$ \\
\hline & il. Madalena Matoso. Alfragide: Caminho, 2010 \\
\hline \multirow{3}{*}{$\begin{array}{l}\text { As cançõezinhas da } \\
\text { Tila } \\
\text { Matilde Rosa Araújo }\end{array}$} & $\begin{array}{l}\text { il. Maria Keil; part. Fernando L. Graça. 1. }{ }^{\text {a }} \text { ed. Porto: } \\
\text { Civilização, } 1998 \text { - Colecção As Palavras Emboscadas }\end{array}$ \\
\hline & $\begin{array}{l}\text { il. Célia Fernandes. 1. }{ }^{\text {a }} \text { ed. Porto: Porto Editora, } 2013 \text { - } \\
\text { Coleção Educação Literária }\end{array}$ \\
\hline & $\begin{array}{l}\text { il. Célia Fernandes. Reimp. Porto: Porto Editora, } 2018 \text { - } \\
\text { Coleção Educação Literária }\end{array}$ \\
\hline \multirow{3}{*}{$\begin{array}{l}\text { O rouxinol e sua } \\
\text { namorada } \\
\text { Sidónio Muralha }\end{array}$} & $\begin{array}{l}\text { il. Fernando Lemos. Lisboa: Livros Horizonte, } 1983 \text { - } \\
\text { Colecção Pássaro Livre }\end{array}$ \\
\hline & $\begin{array}{l}\text { il. Marta Jacinto. } 1 \text {. }^{\text {a }} \text { ed. Porto: Porto Editora, } 2013 \text { - } \\
\text { Coleção Educação Literária }\end{array}$ \\
\hline & 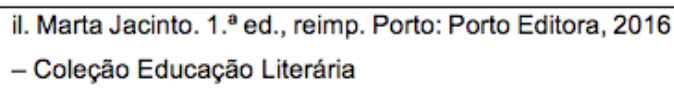 \\
\hline \multirow{2}{*}{$\begin{array}{l}\text { Bichos, bichinhos e } \\
\text { bicharocos } \\
\text { Sidónio Muralha }\end{array}$} & il. Júlio Pomar. Lisboa: Centauro, 1949 \\
\hline & $\begin{array}{l}\text { il. Elsa Fernandes. 1. }{ }^{\text {a }} \text { ed. Porto: Porto Editora, } 2013 \text { - } \\
\text { Coleção Educação Literária }\end{array}$ \\
\hline
\end{tabular}


Quadro 1. Obras de poesia e suas respectivas edições. (Cont.)

\begin{tabular}{|c|c|}
\hline \multirow{3}{*}{$\begin{array}{l}\text { Fala bicho } \\
\text { Violeta Figueiredo }\end{array}$} & $\begin{array}{l}\text { il. Manuela Bacelar. Porto: Asa, } 1992 \text { - Colecção } \\
\text { Benjamin }\end{array}$ \\
\hline & $\begin{array}{l}\text { il. Danuta Wojciechowska. } 4 .^{\text {a }} \text { ed. Lisboa: Caminho, } \\
1999\end{array}$ \\
\hline & $\begin{array}{l}\text { il. Pedro Serapicos. 2014. Porto: Porto Editora, } 2014 \text { - } \\
\text { Coleção Educação Literária }\end{array}$ \\
\hline \multirow{2}{*}{$\begin{array}{l}\text { Poemas da mentira e } \\
\text { da verdade } \\
\text { Luísa Ducla Soares }\end{array}$} & $\begin{array}{l}\text { il. Paula Amaral. Lisboa: Livros Horizonte, } 1983 \text { - } \\
\text { Colecção Pássaro Livre }\end{array}$ \\
\hline & $\begin{array}{l}\text { il. Ana Cristina Inácio. [Reimp.]. Lisboa: Livros Horizonte, } \\
1999\end{array}$ \\
\hline \multirow{3}{*}{$\begin{array}{l}\text { As fadas verdes } \\
\text { Matilde Rosa Araújo }\end{array}$} & $\begin{array}{l}\text { il. Manuela Bacelar. 1. }{ }^{\text {a }} \text { ed. Porto: Civilização, } 1994 \text { - } \\
\text { Colecção As Palavras Emboscadas }\end{array}$ \\
\hline & $\begin{array}{l}\text { il. Abigail Ascenso. 1. a ed. Porto: Porto Editora, } 2014 \text { - } \\
\text { Coleção Educação Literária }\end{array}$ \\
\hline & $\begin{array}{l}\text { il. Abigail Ascenso. Reimp. Porto: Porto Editora, } 2016 \text { - } \\
\text { Coleção Educação Literária }\end{array}$ \\
\hline \multirow{4}{*}{$\begin{array}{l}\text { A cor das vogais } \\
\text { Vergílio Alberto Vieira }\end{array}$} & $\begin{array}{l}\text { il. Jorge Ulisses. Vila Verde: Câmara Municipal, } 1991 \text { - } \\
\text { Livros para a Infância }\end{array}$ \\
\hline & $\begin{array}{l}\text { il. Teresa Lima. Porto: Civilização, } 1994 \text { - Colecção As } \\
\text { Palavras Emboscadas }\end{array}$ \\
\hline & $\begin{array}{l}\text { il. João Caetano. 3. }{ }^{\text {a }} \text { ed. Porto: Campo das Letras, } 2005 \\
\text { - Palmo e Meio }\end{array}$ \\
\hline & $\begin{array}{l}\text { il. Maria João Lopes. 1. a ed. Porto: Porto Editora, } 2013 \text { - } \\
\text { Coleção Educação Literária }\end{array}$ \\
\hline \multirow{2}{*}{$\begin{array}{l}\text { Versos de Cacaracá } \\
\text { António Manuel Couto } \\
\text { Viana }\end{array}$} & $\begin{array}{l}\text { il. Juan Soutullo Lisboa/Porto: Litexa, } 1984 \text { - Contos de } \\
\text { Ontem para Crianças de Hoje }\end{array}$ \\
\hline & il. Vasco Gargalo. $1 .^{a}$ ed. Alfragide: Texto, 2010 \\
\hline $\begin{array}{l}\text { Mistérios } \\
\text { Matilde Rosa Araújo }\end{array}$ & il. Alice Jorge. Lisboa: Livros Horizonte, 1988 \\
\hline
\end{tabular}

Diferentemente do que acontece com as obras de poesia, as de conto de autor não experienciam o esquecimento e apenas um, dos oito títulos analisados, foram reeditados somente após a sua inserção na Lista de Obras e Textos (O mercador de coisa nenhuma, de António Torrado), como pode ser visto no Quadro 2 (Obras de conto de autor e suas respectivas edições). 
Quadro 2. Obras de conto de autor e suas respectivas edições.

\begin{tabular}{|c|c|}
\hline Identificação & Edições \\
\hline \multirow{2}{*}{$\begin{array}{l}\text { A flor vai ver o mar } \\
\text { Alves Redol }\end{array}$} & $\begin{array}{l}\text { il. Leonor Praça. Mem Martins: Europa-América, } 1968 \text { - } \\
\text { Colecção } 6 / 12\end{array}$ \\
\hline & $\begin{array}{l}\text { il. José Miguel Ribeiro. Lisboa: Caminho, } 2006 \text { - Coleção Flor } \\
\text { Maria Flor }\end{array}$ \\
\hline \multirow{2}{*}{$\begin{array}{l}\text { Uma flor chamada } \\
\text { Maria } \\
\text { Alves Redol }\end{array}$} & $\begin{array}{l}\text { il. Fausto Boavida. Mem Martins: Europa-América, } 1969 \text { - } \\
\text { Colecção 6/12 }\end{array}$ \\
\hline & $\begin{array}{l}\text { il. José Miguel Ribeiro. Lisboa: Caminho, } 2007 \text { - Coleção Flor } \\
\text { Maria Flor }\end{array}$ \\
\hline \multirow{3}{*}{$\begin{array}{l}\text { O elefante cor-de-rosa } \\
\text { Luísa Dacosta }\end{array}$} & il. Armando Alves. Porto: Figueirinhas, 1974 \\
\hline & il. Francisco Santarém. 2. ${ }^{a}$ ed. Porto: Civilização, 1996 \\
\hline & $\begin{array}{l}\text { il. Armando Alves. 1. } .^{2} \text { ed. Porto: Asa, } 2005 \text { - Obras completas } \\
\text { de Luisa Dacosta para a Infância }\end{array}$ \\
\hline \multirow{5}{*}{$\begin{array}{l}\text { A menina gotinha de } \\
\text { água } \\
\text { Papiniano Carlos }\end{array}$} & $\begin{array}{l}\text { il. João da Câmara Leme. Lisboa: Portugália, } 1962 \text { - Colecção } \\
\text { Os Pequenos Pioneiros }\end{array}$ \\
\hline & il. João Nunes. Porto: Asa, 1987 - Colecção Asa Juvenil \\
\hline & $\begin{array}{l}\text { il. Joana Quental. 1. }{ }^{a} \text { ed. Porto: Campo das letras, } 1999 \text { - Palmo } \\
\text { e Meio }\end{array}$ \\
\hline & $\begin{array}{l}\text { il. Henrique Cayatte. } 1{ }^{a} \text { ed. Porto: Assírio e Alvim, } 2014 \text { - } \\
\text { Assirinha }\end{array}$ \\
\hline & $\begin{array}{l}\text { il. Henrique Cayatte. 1. }{ }^{a} \text { ed. Porto: Porto Editora, } 2014 \text { - Coleção } \\
\text { Educação Literária }\end{array}$ \\
\hline $\begin{array}{l}\text { A arca do tesouro } \\
\text { Alice Vieira }\end{array}$ & il. João Fazenda. Alfragide: Caminho, 2010 \\
\hline \multirow{2}{*}{$\begin{array}{l}\text { O mercador de coisa } \\
\text { nenhuma } \\
\text { António Torrado }\end{array}$} & $\begin{array}{l}\text { il. Ángela Melo. } .^{a} \text { ed. rev. e aument. Porto: Civilização, } 1994 \text { - } \\
\text { Colecção Obras de António Torrado }\end{array}$ \\
\hline & $\begin{array}{l}\text { il. Tiago Pimentel. } 1{ }^{a} \text { ed. Alfragide: Asa, } 2014 \text { - Biblioteca } \\
\text { António Torrado }\end{array}$ \\
\hline \multirow{2}{*}{$\begin{array}{l}\text { História com recadinho } \\
\text { Luisa Dacosta }\end{array}$} & il. Karin Somero. Porto: Figueirinhas, 1986 \\
\hline & $\begin{array}{l}\text { il. Cristina Valadas. 1. }{ }^{\text { }} \text { ed. Alfragide: Asa II, } 2010 \text { - Obras } \\
\text { completas de Luísa Dacosta para a Infância }\end{array}$ \\
\hline \multirow{5}{*}{$\begin{array}{l}\text { A maior flor do mundo } \\
\text { José Saramago }\end{array}$} & il. João Caetano. Lisboa: Caminho, 2001 \\
\hline & il. João Caetano. 1. ${ }^{a}$ ed. Porto: Porto Editora, 2014 \\
\hline & il. André Letria. Alfragide: Caminho, 2013 \\
\hline & il. André Letria. 2. ${ }^{a}$ ed. Porto: Porto Editora, 2015 \\
\hline & $\begin{array}{l}\text { il. Inês Oliveira. 1. }{ }^{a} \text { ed. Porto: Porto Editora, } 2016 \text { - Coleção } \\
\text { Educação Literária }\end{array}$ \\
\hline
\end{tabular}

Assim, a partir da análise dos percursos editoriais das obras do corpus, é possível constatar, por um lado, o esquecimento editorial e comercial de que sofrem muitos livros de poesia que, por isso, são menos vezes explorados literária e esteticamente em novas edições. Isso circunscreve, em certa medida, as suas possibilidades de leitura e interpretação.

Por outro lado, também se verifica a partir dessa análise que a adoção de obras de poesia em contexto escolar potencializa o seu interesse comercial e editorial. Este, por sua vez, pode vir a gerar a abertura para a criação de mais e novas edições significativas desses livros, fazendo com que, à exemplo do ocorrido com as obras As cançõezinhas da Tila; As fadas verdes; O rouxinol e sua namorada e Bichos, bichinhos e bicharocos, eles passem de esquecidos à relembrados. 


\section{DUAS FACES DA MOEDA}

A edição de Literatura para a Infância, para além da preterição relegada aos livros de poesia, também compartilha com a edição de Literatura "para adultos" o desafio relacionado às formas de organização do mercado editorial. Há algumas décadas, os integrantes da cadeia do livro assistem a um processo de homogeneização do mercado editorial que, cada vez mais, fica sob o domínio de algumas (poucas) casas editoriais. Em Portugal, esse fenômeno de oligopolização do mercado livreiro vem ocorrendo desde o final da primeira década dos anos 2000, a partir da consolidação dos grupos editoriais LeYa e Porto Editora.

0 primeiro foi criado a partir da editora LeYa, atuante nas áreas de edição literária. A partir de 2008, começou a se consolidar como uma das gigantes editoriais portuguesas com a aquisição de outras casas editoriais de tradição e renome, como ASA, Caminho e D. Quixote; e de várias chancelas, como Casa do Livro e Sebenta. No mesmo ano, a Porto Editora, já nesta época considerada a principal editora de materiais didáticos de Portugal, também iniciou o seu processo de ampliação com vistas a se firmar como a referência editorial no ramo escolar e se consolidar como editora de livros literários. Com a agregação de casas editoriais, também tradicionais e renomadas, como Areal, Sextante e Assírio e Alvim, foi constituído o segundo grupo dominante do mercado editorial português.

O cenário editorial bipolarizado que se formou oferece riscos comerciais e financeiros às editoras independentes, que estão constantemente sob o risco de serem esquecidas, extintas ou absorvidas pelos gigantes que controlam o mercado (Thompson, 2012). Diretamente ligado à possível obliteração das editoras independentes (mas não só) está a ameaça que essa conjuntura oligopolizada representa à diversidade editorial dos livros publicados e consumidos/ lidos (Schiffrin, 2006). Isso, porque os grupos editoriais hegemônicos tendem a tomar decisões editoriais ambicionando grandes volume de vendas e margem de lucro. Como consequência, é comum identificar em seus catálogos, majoritariamente, dois tipos de obras: novos títulos, com características relativamente homogêneas e atreladas à modismos, de forma a atender os gostos e interesses do maior número de pessoas possível; e títulos canônicos, que, se por um lado, asseguram um público consumidor consolidado, por outro, normalmente têm um custo de direitos autorais associado que somente casas editoriais com um patrimônio financeiro robusto podem custear.

Somando-se, então, a estabilidade e a rentabilidade que edições voltadas para o contexto escolar asseguram por conta de seu público cativo ao estatuto canônico que os títulos que figuram na Lista de Obras e Textos detêm no contexto de Literatura para a Infância, não surpreende que eles despertem o interesse dos grandes grupos editoriais, que passam a ser, portanto, os responsáveis pela publicação da maioria desses livros.

Pela análise do percurso editorial das obras de poesia e conto de autor de autoria portuguesa que devem, segundo o Programa e as Metas Curriculares do Português do Ensino Básico, ser lidas nos anos escolares do 1. - Ciclo, foi possível constatar o domínio das editoras dos grupos LeYa e Porto Editora a partir da promulgação da política educativa. Observou-se que, desde 2012, editoras pertencentes aos dois grupos detém o direito de edição e comercialização de dezessete das dezenove obras integrantes do corpus desta pesquisa. Nove delas, inclusivamente, foram publicados sob a Coleção Educação Literária, de caráter econômico e escolar, criada pela Porto Editora com o objetivo de atender as demandas criadas pela Lista de Obras e Textos. 
A supremacia editorial de LeYa e Porto Editora ficam evidentes também a partir da análise dos peritextos dos livros por elas editados e publicados. 0 elemento que mais chama atenção é o tratamento estético dado pelas editoras às lombadas. Aparentemente ingênuo, esse peritexto exerce fundamentalmente o papel estrutural de unir a capa à contracapa, fazendo parte da encadernação. Apesar do pouco espaço, as lombadas quadradas, presentes em livros cujos cadernos são colados ou costurados, podem exercer também uma função prática e editorial a partir da exposição de elementos de identificação, como "the name of the author, the colophon of the publisher, and the title of the work" (Genette, 1997, p. 26). Esses dados costumam ser expostos horizontalmente, em livros com lombadas mais largas e, em lombadas mais estreitas, verticalmente, ora sob a orientação ascendente, conhecida tradicionalmente como latina ou francesa; ora sob a orientação descendente, nomeada anglo-saxã ou inglesa.

A opção por uma ou outra disposição vertical da lombada está historicamente associada às tradições dos países fundantes do exercício da edição, França e Inglaterra. Atualmente, ela também costuma indicar a tipologia editorial da obra, sendo mais comum encontrar livros ficcionais com lombadas ascendentes, e livros não-ficcionais com lombadas descendentes. No cenário editorial português, caracterizado pela dominação dos dois grupos anteriormente apresentados, a disposição vertical das lombadas serve também para reafirmar a bipolarização do mercado, uma vez que ela é utilizada como fator distintivo entre os livros publicados pela LeYa e pela Porto Editora.

De entre as edições analisadas constituídas de lombadas não-silenciosas, ou seja, com a impressão de alguma informação verbal ou iconográfica, foi possível constatar que, por conta de sua vertente originalmente mais vinculada à edição literária, as editoras do grupo LeYa publicam os seus livros com lombadas ascendentes. Em contrapartida, os livros editados pelas casas constituintes do grupo Porto Editora apresentam lombadas descendentes, respeitando, assim, a sua tradição em edição escolar e, portanto, não-ficcional.

Dessa forma, os grupos editoriais dominantes dividem irmãmente não só os espaços nas prateleiras e sites do comércio livreiro e na Lista de Obras e Textos, como também a forma de edição das lombadas, que passam a agregar às suas funções o papel de constituição de identidade visual de duas marcas, que, dessa forma, se distinguem uma da outra, mesmo que apenas a menor superfície dos livros por elas publicados esteja exposta.

\section{ECOS DO LIVRO-ÁLBUM}

A ausência de livros-álbum de autoria portuguesa na Lista de Obras e Textos, defende-se neste artigo, deveria ser revista de modo a contemplar autores e obras reconhecidos ao nível acadêmico pelas suas potencialidades educativas na formação de leitores, uma vez que títulos assinados, por exemplo, pelos criadores André Letria, Catarina Sobral, Isabel Minhós Martins, João Fazenda e Manuela Bacelar poderiam representar um benefício para leitores em fase inicial de aprendizagem da leitura.

Este formato editorial, criado e desenvolvido por volta de 1960, oferece aos seus leitores a possibilidade de desenvolver senso estético e habilidades e competências voltadas para a realização de uma leitura híbrida e multimodal, já que é "habitualmente definido pelos seus elementos paratextuais" e pela "sinergia ou simbiose entre texto, ilustração e suporte" (Ramos, 2020, p. 174), materializados, por exemplo, em elementos peritextuais, estéticos e materiais como a capa dura, as dimensões e o formato, a qualidade do papel e o tipo de impressão em quadricomia, para além 
do reduzido número de páginas (32) e da presença de muitas ilustrações [sendo que] o livroálbum contemporâneo aposta cada vez mais no recurso à página dupla como unidade de sentido, na inclusão de um texto de reduzida extensão, apresentado com carateres de grande dimensão (Ramos, 2020, p. 174).

No entanto, enquanto títulos de livros-álbum não são incluídos na Lista de Obras e Textos, suas características vêm se fazendo presentes nas leituras obrigatórias dos anos iniciais das escolas portuguesas a partir de ecos estéticos e materiais que vão surgindo nas novas edições de livros de poesia e conto de autor que, esses sim, já figuram na lista. De acordo com Ramos (2020), essa é uma tendência editorial em ascensão, tendo em vista que, cada vez mais, "as principais características do formato do livro-álbum têm vindo a influenciar outros tipos de publicações para crianças (e mesmo para adultos)" (p. 186). Por meio da análise dos peritextos e do percurso editorial das obras de poesia e conto de autor de autoria portuguesa de leitura obrigatória nos primeiros quatro anos de escolarização em Portugal, constatou-se a presença de "contaminações" do livro-álbum em livros reeditados e publicados a partir, principalmente, da primeira década dos anos 2000.

De entre eles, chama a atenção a mudança no paradigma de paginação das capas de edições tradicionais mais recentes. Se comparadas às tendências majoritárias das publicações do século XX, as capas editadas a partir de meados da década de 1990 exibem ilustrações maiores, que, por vezes, funcionam como plano de fundo para os demais elementos gráficos e verbais que as compõem. Um exemplo dessa tendência pode ser verificado através da observação das duas edições de $O$ elefante cor-de-rosa, de Luísa Dacosta, ilustradas por Armando Alves (Figura 1: Capas de $O$ elefante cor-derosa). Se, na primeira versão, publicada em 1974, a ilustração da capa fica circunscrita a uma área relativamente pequena, localizada no centro da capa, envolta por uma moldura colorida, onde são dispostos, em destaque, os demais elementos textuais e gráficos; na segunda, editada em 2005, a mesma ilustração é redimensionada de forma a ocupar toda a capa, com as informações verbais e gráficas dispostas em subordinação à ilustração.

Figura 1. Capas de O elefante cor-de-rosa

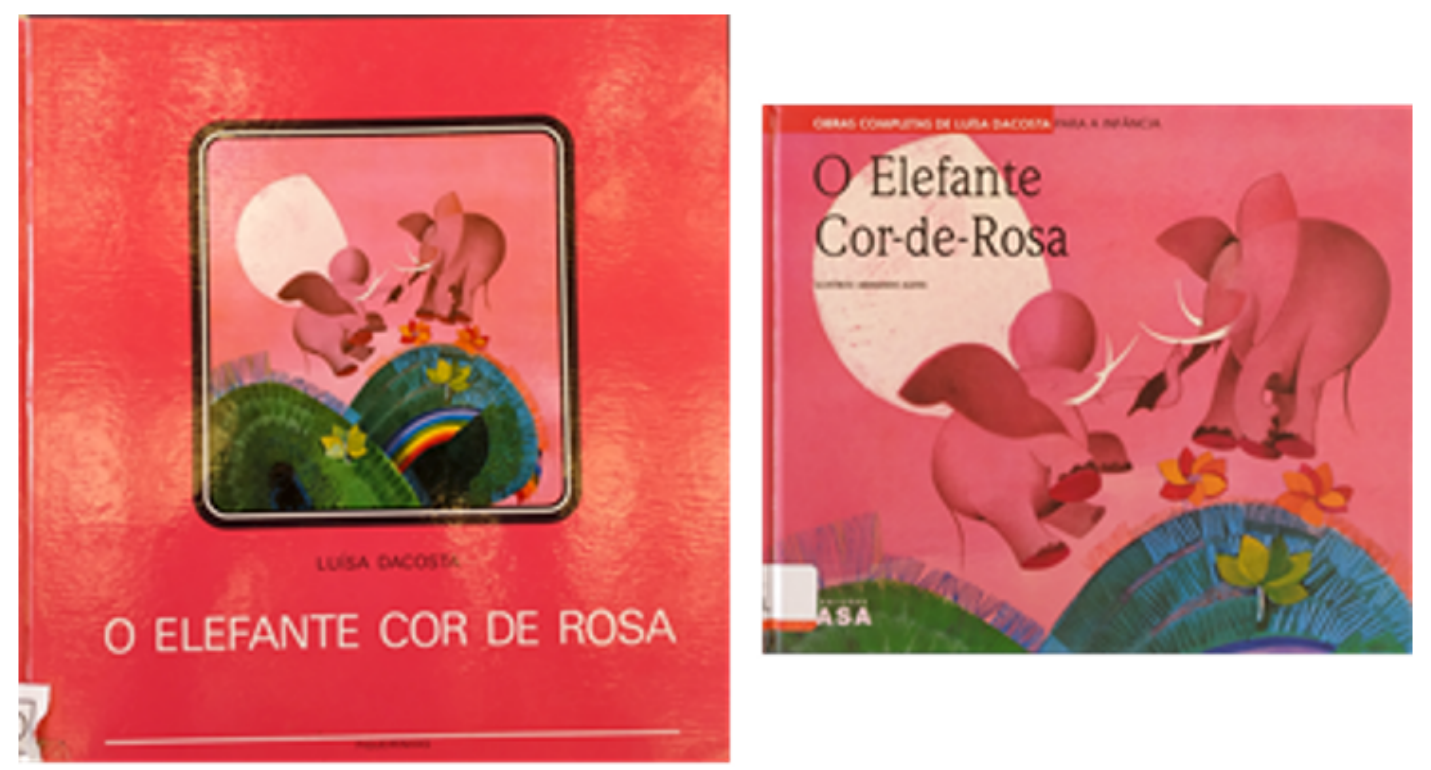

A análise das capas também possibilitou a constatação de que o apreço do livro-álbum pela página dupla como unidade de significação influenciou a edição de obras de outros formatos, haja 
vista a maior opção por esse modelo de paginação identificada nas capas dos títulos editados nas últimas décadas. Dessa forma, a capa e a contracapa são unidas pela lombada para, além de cumprir a sua função estrutural de proteção do miolo, formar, em conjunto, um "cartão de visita da obra" (Ribeiro, 2000, p. 375). Essa página dupla de cobertura, visível apenas quando o livro fica todo aberto, é incumbida de criar "uma expectativa no leitor, uma prévia do que ele encontrará" (Romani, 2011, p. 28) e apresentar a obra ao público com indicações de tema, tom e destinatário (Martinez, Stier e Falcon, 2016; Nikolajeva e Scott, 2006) a partir da "contemplação e leitura do título, da imagem, do formato, da informação da quarta capa etc." (Colomer, 2018, p. 275). Essa configuração é visível, por exemplo, nas capas das obras O livro da Tila, de Matilde Rosa Araújo com ilustrações de Madalena Matoso, publicado em 2010; e Versos de Cacaracá, de António Manuel Couto Viana, publicado no mesmo ano e ilustrado por Vasco Gargalo (Figura 2: Capas de O livro da Tila e Versos de Cacaracá).

Figura 2. Capas de O livro da Tila e Versos de Cacaracá.
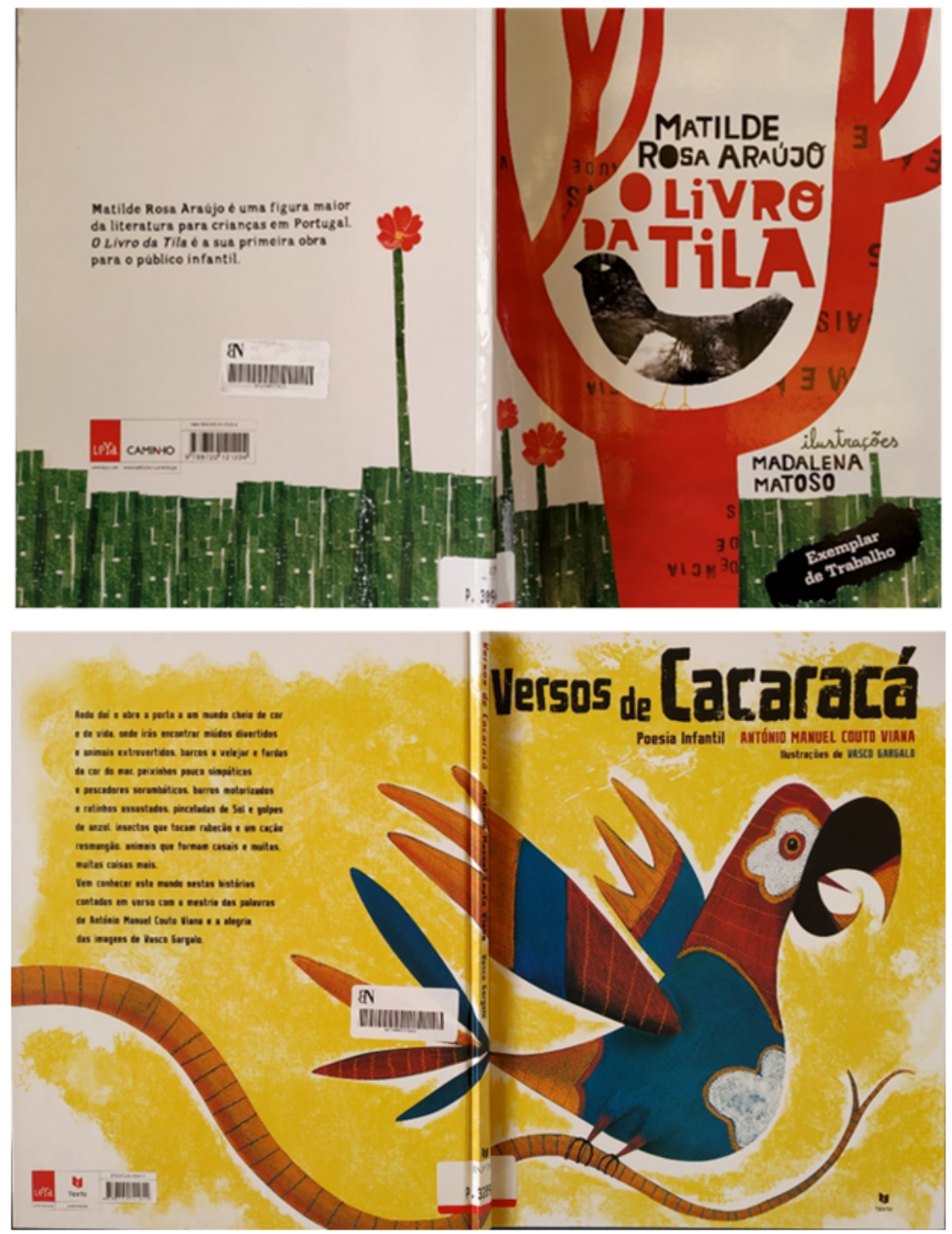

Ao abrir essas duas obras, é possível constatar que também as suas guardas assumiram características próprias do livro-álbum, uma vez que já não podem ser consideradas mudas, 
conforme proposto por Genette (1989), ou descrita apenas como "sheets of paper glued to book covers in order to secure them to the text block [...] a part of the technical requirements of the binding process" (Duran e Bosch, 2011, p. 122). Por meio da observação de O livro da Tila e de Versos de Caracacá (Figura 3: Guardas de O livro da Tila e Versos de Caracacá), é possível constatar que, de acordo com a tipologia de categorização proposta por Consejo Pano, em seu texto "Peritextos del siglo XXI. Las guardas en el discurso literario infantil" (2011), ambos os livros apresentam guardas consideradas ilustradas com significado próprio, atribuindo, pelas mãos dos ilustradores, elementos estéticos e literários significativos em espaços antes vazios e silenciosos.

Figura 3. Guardas de O livro da Tila e Versos de Caracacá.
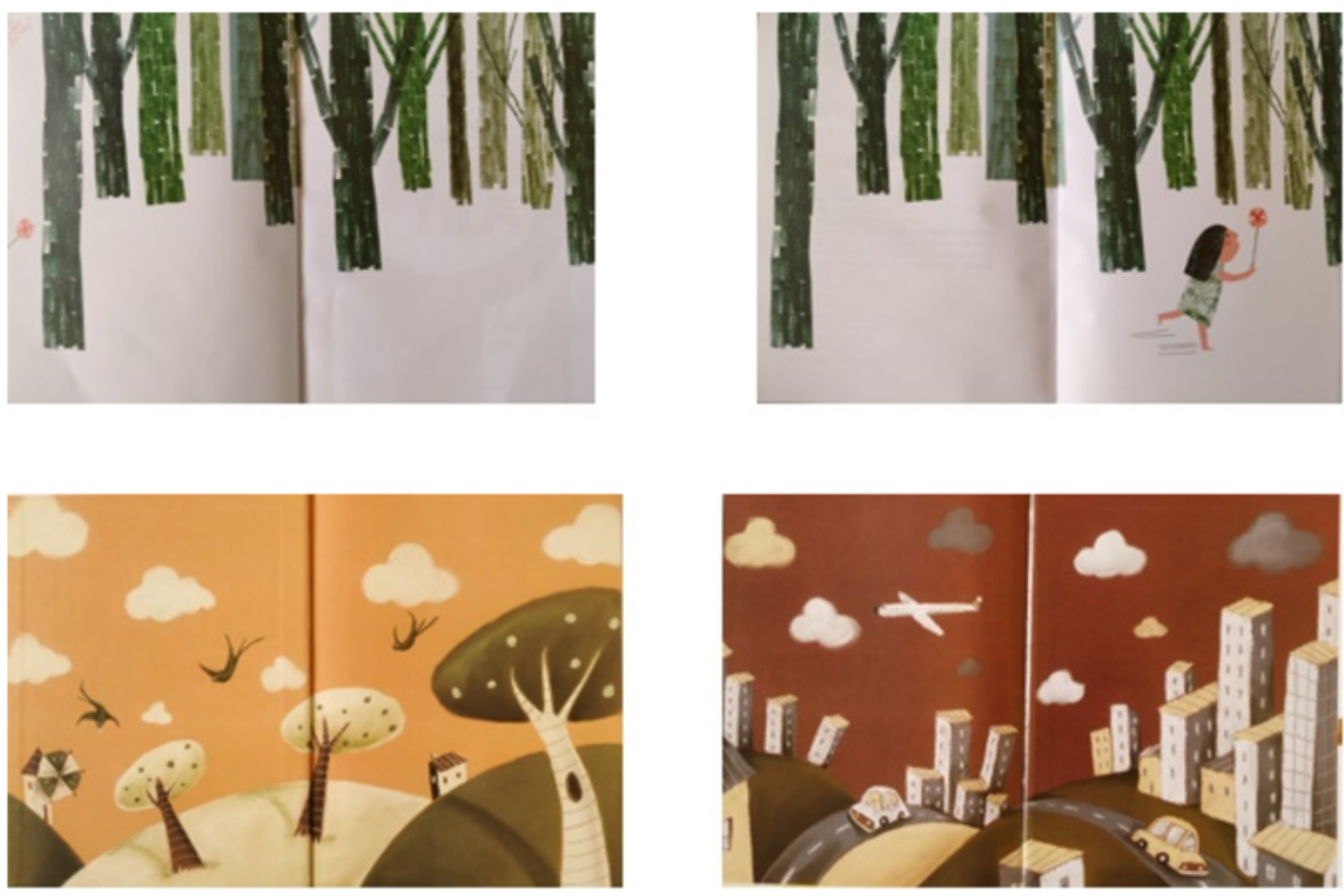

Tendo em vista que as ilustrações são de autoria, respectivamente, de Madalena Matoso e do cartunista Vasco Gargalo, a adoção de características estéticas próprias do livro-álbum nessas duas obras, constatada pela análise de seus peritextos de cobertura, é compreensível. Isso, porque ambos os ilustradores são reconhecidos em suas áreas por trabalharem predominantemente em obras construídas a partir da conjugação de texto verbal, quando presente, com ilustrações, que ganham maior destaque no processo de significação da obra.

As edições apresentadas de $O$ livro de Tila e Versos de Cacaracá, assim como a de $O$ elefante corde-rosa, demonstram a extensão do impacto do livro-álbum na edição de livros para a infância. Constata-se, com isso, que atributos próprios dos livros-álbuns podem ser (e vêm sendo) adotados por outros formatos de livro, garantindo, assim, um maior interesse estético e um aumento nas possibilidades de extensão de significados das obras de Literatura para a Infância a partir de estratégias como a exploração de elementos peritextuais que antes exerciam somente funções estruturais; ou a valorização de relações diferenciadas entre o texto verbal e o não-verbal, conforme identificado nas edições expostas nesta sessão e em outras obras mais atuais. 


\section{CONSIDERAÇÕES}

A pesquisa retratada neste artigo teve como objetivo principal realizar a caracterização do percurso editorial das obras que compuseram o corpus e, a partir da análise dos peritextos capa, contracapa, lombada e guardas de cada uma das suas edições significativas, identificar o impacto editorial recente, decorrente da sua inserção na lista de livros de leitura obrigatória ou sugerida no Programa e nas Metas Curriculares de Português do Ensino Básico. De entre os resultados obtidos e analisados ao longo do desenvolvimento do projeto, foram salientados neste texto três, considerados como tendências da edição de Literatura para a Infância no cenário editorial português.

A primeira dessas tendências relaciona-se com o poder legitimador exercido pelas instituições escolares e pelas políticas públicas educativas nos contextos de produção, edição e publicação de Literatura (para a Infância). Considerado como um dos principais pilares de reconhecimento e canonização de obras literárias, as escolas e as políticas públicas a elas associadas têm também um importante papel na manutenção do interesse comercial e mercadológico de livros de literatura. Isso, porque, ao garantir aos títulos selecionados para serem lidos e estudados um público consumidor estável e lucrativo, possibilita que eles sejam editados e reeditados por editoras e grupos editoriais que, cada vez mais, atuam em função da lógica de mercado voltada para a obtenção do lucro máximo.

Dessa forma, livros que poderiam ser esquecidos pelo seu pouco apelo comercial de massa, são relembrados e continuam a existir nos catálogos de casas editoriais e nas prateleiras das livrarias, conforme aconteceu com as obras As cançõezinhas da Tila; As fadas verdes; $O$ rouxinol $e$ sua namorada e Bichos, bichinhos e bicharocos.

Mesmo que os objetivos da pesquisa não tenham abordado questões de caráter educativo e de formação dos leitores, faz-se necessário ressaltar que o papel da escola não se circunscreve a, por meio de uma lista de livros de leitura obrigatória, criar uma demanda virtual por livros que, normalmente, não venderiam. Acredita-se que, na verdade, a leitura e o estudo dessas obras poderão, à longo prazo, proporcionar a formação de leitores críticos, habilitados e sensíveis que, orgânica e naturalmente, possam vir a nutrir esses nichos do mercado livreiro, hoje colocados à margem.

Em posição marginal também estão as editoras independentes, que praticamente não gozam das vantagens conseguidas por meio da promulgação de políticas públicas como as Metas Curriculares e a sua lista de leituras obrigatórias. A segunda tendência identificada por meio da pesquisa retratada neste trabalho verifica o possível sufocamento comercial que acomete casas editoriais não englobadas nos dois grupos dominantes no cenário português: LeYa e Porto Editora. Esses grupos, donos de editoras e chancelas tradicionais, possuem um capital econômico robusto, que lhes possibilita poder e influência suficientes para, por exemplo, adquirir os direitos de publicação mais concorridos, desejados e rentáveis, como aqueles canônicos que figuram na Lista de Obras e Textos. Assim, com vistas a usufruir dos ganhos proporcionados pelo mercado estável dos livros de Literatura para a escola, LeYa e Porto Editora reeditaram obras, conquistaram direitos de autor e criaram coleções especializadas para o nicho escolar de modo que, atualmente, dividem irmãmente o seu controle.

Essa bipolarização é visível não só na hegemonia exercida pelas duas editoras, que, dos dezenove títulos de poesia e conto de autor de autoria portuguesa lidos nos anos do 1.ํ Ciclo, publicam 
dezessete. É também identificada em elementos peritextuais, como as lombadas, que assumem a orientação ascendente nos livros editados pela LeYa, e descendentes nos da Porto Editora, que, dessa forma, marcam seu lugar de domínio mesmo que os livros estiverem todos dispostos nas estantes pelas lombadas.

Para evitar que o cenário português experencie um processo de homogeneização editorial, defende-se que a escola, através de seu papel legitimador, referido anteriormente, deveria atuar em função do reconhecimento e da promoção de leituras de obras de editoras, gêneros, temáticas, estéticas e autores que ocupam as margens. Para isso, deveria incluir nas suas listas mais do que textos já canonizados, escritos majoritariamente por homens de meados do século XX, como acontece na Lista de Obras e Textos. Acredita-se que abrir as portas das políticas educativas voltadas para a promoção da leitura e da formação leitora à novas tendências estéticas e materiais, autores desconhecidos, temáticas vigentes e editoras independentes possa ser um bom caminho para garantir a diversidade cultural e literária não só nas editoras e livrarias, mas no cânone e no imaginário coletivo do que é considerado a boa Literatura.

Um dos formatos estéticos e materiais ignorados pela Lista de Obras e Texto, por exemplo, é o livro-álbum. Reconhecido ao nível acadêmico, nacional e internacionalmente, pelas suas potencialidades na formação do leitor, a sua ausência no rol de livros de autoria portuguesa que devem ser lidos pelos estudantes do 1. Ciclo em escolas de Portugal espelha a pouca atenção que é dada pelas Metas Curriculares ao desenvolvimento de habilidades e competências necessárias para a leitura dos elementos constituintes de uma obra de Literatura para a Infância que não o texto verbal. Assim, são poucos os tópicos de ensino e de aprendizagem em Educação Literária voltados para o desenvolvimento da leitura competente dos elementos peritextuais e da relação entre texto verbal, ilustração e suporte, tão importantes e presentes nas edições dos livros-álbum.

A despeito disso e conforme aponta a terceira tendência de edição de Literatura para a Infância constatada na pesquisa desenvolvida, as características peritextuais e estéticas próprias do livroálbum fazem-se presentes na Lista de Obras e Textos a partir de ecos e contaminações nas novas edições, publicadas a partir dos anos 2000, de livros de poesia e conto de autor, como $O$ elefante cor-de-rosa, o livro da Tila e Versos de Cacaracá.

Tendo isso em vista, argumenta-se mais uma vez em favor da importância da inclusão de livros-álbum nas eventuais futuras listas de leituras feitas em contexto escolar e, principalmente, do desenvolvimento de objetivos de ensino e de aprendizagem que promovam a formação de leitores críticos e competentes para a leitura e a fruição de textos multimodais e híbridos, de diversos gêneros, que abordem múltiplas temáticas, sob as mais variadas tendências estéticas. Também se sugere o desenvolvimento de outros estudos que abordem os livros de Literatura para a Infância adotados em contextos escolares sob a perspectiva da sua análise peritextual, com vistas a corroborar a importância da sua exploração para a construção e expansão de significados. Além disso, importa também dizer que se acredita que este estudo, de caráter iniciático, possa constituir um contributo relevante para o estudo das relações entre o universo editorial e as políticas educativas, sobretudo tendo em vista o impacto das decisões programáticas na edição. Procurou-se, nesta abordagem exploratória, identificar algumas dessas relações e compreender melhor, através da sua caracterização, do ponto de vista editorial, os materiais de leitura disponíveis em Portugal, bem como a sua evolução nos últimos anos. 


\section{Bibliografía}

\section{Obras analisadas}

\section{Contos de autor}

Carlos, P. (1962). A menina Gotinha de Água [Ilust. João da Câmara Leme]. Portugália.

Carlos, P. (1987). A menina Gotinha de Água [Ilust. João Nunes]. Asa.

Carlos, P. (1999). A menina Gotinha de Água [Ilust. Joana Quental]. Campo das Letras.

Carlos, P. (2014). A menina Gotinha de Água [Ilust. Henrique Cayatte]. Assírio e Alvim.

Carlos, P. (2014). A menina Gotinha de Água [Ilust. Henrique Cayatte]. Porto Editora.

Dacosta, L. (1974). O elefante cor-de-rosa [Ilust. Armando Sales]. Figueirinhas.

Dacosta, L. (1986). História com recadinho [Ilust. Karin Somero]. Figueirinhas.

Dacosta, L. (1996). O elefante cor-de-rosa [Ilust. Francisco Santarém, 2. ed]. Civilização.

Dacosta, L. (2005). O elefante cor-de-rosa [Ilust. Armando Sales]. Asa.

Dacosta, L. (2010). História com recadinho [Ilust. Cristina Valadas]. Asa.

Redol, A. (1968). A flor vai ver o mar [Ilust. Leonor Praça]. Publicações Europa-América.

Redol, A. (1969). Uma flor chamada Maria [Ilust. Fausto Boavida]. Publicações Europa-América.

Redol, A. (2006). A flor vai ver o mar [Ilust. José Miguel Ribeiro]. Caminho.

Redol, A. (2007). Uma flor chamada Maria [Ilust. José Miguel Ribeiro]. Caminho.

Saramago, J. (2001). A maior flor do mundo [Ilust. João Caetano]. Caminho.

Saramago, J. (2013). A maior flor do mundo [Ilust. André Letria]. Caminho.

Saramago, J. (2014). A maior flor do mundo [Ilust. João Caetano]. Porto Editora.

Saramago, J. (2015). A maior flor do mundo [Ilust. André Letria, 2. a ed.]. Porto Editora.

Saramago, J. (2016). A maior flor do mundo [Ilust. Inês Oliveira]. Porto Editora.

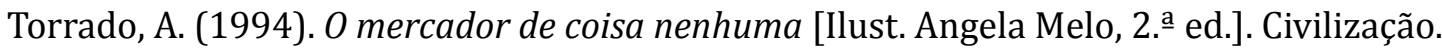

Torrado, A. (2014). O mercador de coisa nenhuma [Ilust. Tiago Pimentel]. Asa.

Vieira, A. (2010). A arca do tesouro [Ilust. João Fazenda]. Caminho.

\section{POESIA}

Araújo, M. R. (1957). O livro da Tila. Editorial Os Nossos Filhos.

Araújo, M. R. (1968). O livro da Tila. Atlântida Editora.

Araújo, M. R. (1986). O livro da Tila [10. ed]. Livros Horizonte.

Araújo, M. R. (1988). Mistérios [Ilust. Alice Jorge]. Livros Horizonte.

Araújo, M. R. (1994). As fadas verdes [Ilust. Manuela Bacelar]. Civilização.

Araújo, M. R. (1998). As cançõezinhas da Tila [Ilust. Maria Keil]. Civilizações.

Araújo, M. R. (2010). O livro da Tila [Ilust. Madalena Matoso]. Caminho.

Araújo, M. R. (2013). As cançõezinhas da Tila [Ilust. Célia Fernandes]. Porto Editora.

Araújo, M. R. (2014). As fadas verdes [Ilust. Abigail Ascenso]. Porto Editora.

Araújo, M. R. (2016). As fadas verdes [Ilust. Manuela Bacelar]. Civilização. 
Araújo, M. R. (2018). As cançõezinhas da Tila [Ilust. Célia Fernandes]. Porto Editora. Eugenio, A. (1986). Aquela nuvem e outras [Ilust. Júlio Resende]. Asa.

Eugenio, A. (1989). Aquela nuvem e outras [Ilust. Jorge Colombo]. Círculo de Leitores.

Eugenio, A. (1999). Aquela nuvem e outras [Ilust. Alfredo Martins]. Campo das Letras.

Eugenio, A. (2013). A cor das vogais [Ilust. Maria João Lopes]. Porto Editora.

Eugenio, A. (2013). Aquela nuvem e outras [Ilust. Aurélie de Sousa]. Porto Editora.

Eugenio, A. (2013). Aquela nuvem e outras [Ilust. Cristina Valadas]. Assírio e Alvim.

Eugenio, A. (2016). Aquela nuvem e outras [Ilust. Aurélie de Sousa, 2. a ed]. Porto Editora.

Figueiredo, V. (1992). Fala Bicho [Ilust. Manuela Bacelar]. Asa.

Figueiredo, V. (1999). Fala Bicho [Ilust. Danuta Wojciechowska, 4. ${ }^{\mathrm{a}}$ ed]. Caminho.

Figueiredo, V. (2014). Fala Bicho [Ilust. Pedro Serapicos]. Porto Editora.

Muralha, S. (1949). Bichos, bichinhos e bicharocos [Ilust. Júlio Pomar]. Livros horizonte.

Muralha, S. (1983). O rouxinol e sua namorada [Ilust. Fernando Lemos]. Livros Horizontes.

Muralha, S. (2013). Bichos, bichinhos e bicharocos [Ilust. Elsa Fernandes]. Porto Editora.

Muralha, S. (2013). O rouxinol e sua namorada [Ilust. Marta Jacinto]. Porto Editora.

Muralha, S. (2016). O rouxinol e sua namorada [Ilust. Marta Jacinto]. Porto Editora.

Soares, L. D. (1983). Poemas da mentira e da verdade [Ilust. Paula Amaral]. Livros Horizonte.

Soares, L. D. (1999). Poemas da mentira e da verdade [Ilust. Ana Cristina Inácio]. Livros Horizonte.

Viana, A. M. C. (1984). Versos de Cacaracá [Ilust. Juan Soutullo]. Litexa.

Viana, A. M. C. (2010). Versos de Cacaracá [Ilust. Vasco Gargalo]. Texto.

Vieira, V. A. (1991). A cor das vogais [Ilust. Jorge Ulisses]. Câmara Municipal.

Vieira, V. A. (1994). A cor das vogais [Ilust. Teresa Lima]. Civilização.

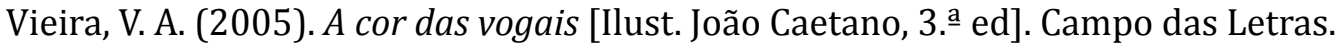

\section{Referências e textos teóricos}

Colomer, T. (2017). Introdução à literatura infantil e juvenil atual. Global.

Consejo Pano, E. (2011). Peritextos del siglo XXI. Las guardas en el discurso literario infantil. Ocnos, 7, 111-122. https://doi.org/10.18239/ocnos_2011.07.09

Dauster, T. (2004). A fabricação de livros infanto-juvenis e os usos escolares - o olhar de editores. I Seminário Brasileiro Sobre o Livro e História Editorial, Brasil. http://www.livroehistoriaeditorial.pro.br/trabalh os4.php

Duran, T. e Bosch, E. (2011). Before and After the Picturebook Frame: a typology of endpapers. New Review of Children's Literature and Librarianship, 17(2), 122-143. https://doi.org/10.1080/13614541.2011.6 24927

Genette, G. (1997). Paratexts: Thresholds of Interpretation. Translated by Jane E. Lewin. Cambridge University Press.

Gomes, J. A. (1998). Para um História da Literatura Portuguesa para a Infância e a Juventude. Ministério da Cultura/IPLB.

Higonnet, M. R. (1990). The playground of the peritexts. Children's Literature Association Quarterly, 15(2), 47-49. https://doi.org/10.1353/chq.0.0831 
Martinez, M., Stier, C. e Falcon, L. (2016). Judging a Book by Its Cover: An Investigation of Peritextual Features in Caldecott Award Books. Children's Literature in Education, 47(3), 225-241. https://doi.org/10.100 7/s10583-016-9272-8

Ministério da Educação e Ciência (2015). Programa e Metas Curriculares de Português para o Ensino Básico. https://www.dge.mec.pt/portugues

Nikolajeva, M. e Scott, C. (2006). How picturebooks work. Nova York.

Ramos, A. M. (2012). Tendências contemporâneas da literatura portuguesa para a infância e juventude. Tropelias e Companhia.

Ramos, A. M. (2020). Hibridismos e contaminações: a propósito do livro-álbum como formato omnívoro. Em P. A. Pereira, E. Madalena e I. Costa (Coord.), Mix e Match - Poéticas do Hibridismo (pp. 173-194). Lúmus.

Ribeiro, M. (2000). Planejamento visual gráfico. Linha Gráfica Editora.

Romani, E. (2011). Design do livro-objeto infantil [Dissertação de Mestrado]. Universidade de São Paulo. htt ps://doi.org/10.11606/D.16.2011.tde-11012012-115004

Sapiro, G. (2019). Publishing Poetry in Translation: An Inquiry into the Margins of the World Book Market. Em J. Blakesley (Ed.), Sociologies of Poetry Translation (pp. 23-44). Bloomsbury. https://doi.org/10.5 040/9781350043282.ch-002

Saraiva, F. O. (2012). Literatura, consumo e ideologia: a construção de perfis da infância em três momentos do mercado editorial infantil brasileiro [Dissertação de Mestrado]. Universidade Federal do Ceará. http:// www.repositorio.ufc.br/handle/riufc/8111

Schiffrin, A. (2006). O negócio dos livros: como as grandes corporações decidem o que você lê. Casa da Palavra. Thompson, J. N. (2012). Merchants of culture. Polity.

Weber, R. P. (1990). Basic Content Analysis. Sage.

Cómo citar este artículo: Jove Godoy, A. (2021). Tendências editoriais e impactos de políticas educativas na publicação de Literatura para a Infância em Portugal. Elos. Revista de Literatura Infantil e Xuvenil, 8, “Artigos", 1-16. ISSN-e 2386-7620. DOI http://dx.doi.org/10.15304/elos.8.7985 